\title{
SCADoC
}

Infer, Interpret \& Inspire Science

International Journal of Dentistry and Oral Science (IJDOS)

ISSN: $2377-8075$

\section{Awareness about Medicinal application of Gold Nanoparticles among Dental Students}

Research Article

Dhanraj Ganapathy ${ }^{1 *}$, Martina Catherine ${ }^{2}$

${ }^{1}$ Professor \& Head of Department, Department of Prosthodontics, Saveetha Dental College and Hospitals, Saveetha Institute of Medical and Technical Sciences, Chennai, India.

${ }^{2}$ Tutor, Department of Prosthodontics, Saveetha Dental College and Hospitals, Saveetha Institute of Medical and Technical Sciences, Chennai, India.

\section{Abstract}

Introduction: Gold nanoparticles offer a wide range of uses, but when monodispersity is required, practical limits become obvious. Over the last 40 years, significant progress has been made in the manufacturing of gold nanoparticles with monodispersity and regulated size. The application of gold nanoparticles in biological and pharmaceutical fields, such as ultrasensitive detection and imaging approaches for bio reorganizing processes, is particularly appealing due to their unique optical features. Aim: This survey was conducted for assessing the awareness about medicinal application of Gold nanoparticles amongst dental students.

Materials and Method: A cross-section research was conducted with a self-administered questionnaire containing ten questions distributed amongst 100 dental students. The questionnaire assessed the awareness about Gold nanoparticles therapy in medical applications, their anti-cancer properties, biodelivery applications, photothermal effects, DNA detection and Gene Diagnostic properties. The responses were recorded and analysed.

Results: $18 \%$ of the respondents were aware of the medicinal applications of Gold Nanoparticles $.15 \%$ were aware of anticancer properties of Gold Nanoparticles, $13 \%$ were aware of biodelivery applications of Gold Nanoparticles, $10 \%$ were aware of photothermal effects of Gold Nanoparticles, $10 \%$ were aware of DNA detection properties of Gold Nanoparticles and, $8 \%$ were aware of Gene Diagnostic properties of Gold Nanoparticles.

Conclusion: There is limited awareness amongst dental students about use of Gold nanoparticles therapy in medical applications. Enhanced awareness initiatives and dental educational programmes together with increased importance for curriculum improvements that further promote knowledge and awareness of Gold nanoparticles therapy.

Keywords: Awareness; Gold; Nanoparticles; Students; Medicinal.

\section{Introduction}

Nanobiotechnology is a rapidly developing field in the analytical and biological sciences for the development of ultrasensitive detection and imaging tools. In current sciences, the interaction of nanotechnology with biology, chemistry, physics, and medicine is extremely important. The increasing availability of nanostructures with controlled optical characteristics has sparked interest in diagnostic and biological imaging applications [1, 2].

Nanoparticles have a higher permeability and retention impact in tumour tissues than in healthy cells, resulting in higher nanoparticle accumulation in tumour tissues. In addition to diagnostic advancements, nanotechnology improves the therapeutic index in cancer therapy, which is a measure of benefit to risk ratio. Nanoparticles' high surface area to volume ratio is also useful for loading medicines, enhancing solubility, stability, and pharmacokinetic characteristics [3].

Gold nanoparticles offer a wide range of uses, but when monodispersity is required, practical limits become obvious. Over the last 40 years, significant progress has been made in the manufacturing of gold nanoparticles with monodispersity and regulated size. The preparation of gold nanoparticles of various sizes is accomplished by reducing gold in the presence of a stabilizing chemical that inhibits particle aggregation. Gold nanoparticles have plasma resonance and a large surface area, which distinguishes them from other types of nanoparticles such as organic,

\section{*Corresponding Author:}

Dhanraj Ganapathy,

Professor \& Head of Department, Department of Prosthodontics, Saveetha Dental College and Hospitals, Saveetha Institute of Medical and Technical Sciences, Chennai, India. Tel: 9841504523

E-mail: dhanrajmganapathy@yahoo.co.in

Received: September 12, 2021

Accepted: September 20, 2021

Published: September 21, 202

Citation: Dhanraj Ganapathy, Martina Catherine. Awareness about Medicinal application of Gold Nanoparticles among Dental Students. Int J Dentistry Oral Sci. $2021 ; 8(9): 4355-4358$. doi: http://dx.doi.org/10.19070/2377-8075-21000886

Copyright: Dhanraj Ganapathy ${ }^{\circ} 2021$. This is an open-access article distributed under the terms of the Creative Commons Attribution License, which permits unrestricted use, distribution and reproduction in any medium, provided the original author and source are credited. 
inorganic, and protein-based nanoparticles. The application of gold nanoparticles in biological and pharmaceutical fields, such as ultrasensitive detection and imaging approaches for biore organizing processes, is particularly appealing due to their unique optical features (surface plasma resonance [SPR] absorption and resonance light scattering) $[4,5]$. Nanotechnology, which involves biology, chemistry, medicine and engineering, has a great potential for diagnosis and treatment of cancer. Our research experience has prompted us in pursuing this research [6-17]. This survey was conducted for assessing the awareness about medicinal application of Gold nanoparticles amongst dental students.

\section{Materials and Methods}

A cross-section research was conducted with a self-administered questionnaire containing ten questions distributed amongst 100 dental students. The questionnaire assessed the awareness about Gold nanoparticles therapy in medical applications, their anticancer properties, biodelivery applications, photothermal effects, DNA detection and Gene Diagnostic properties. The responses were recorded and analysed.

\section{Results}

$18 \%$ of the respondents were aware of the medicinal applications of Gold Nanoparticles (Fig 1). $15 \%$ were aware of anticancer properties of Gold Nanoparticles (Fig 2), $13 \%$ were aware of biodelivery applications of Gold Nanoparticles (Fig 3), $10 \%$ were aware of photothermal effects of Gold Nanoparticles (Fig 4), 10\% were aware of DNA detection properties of Gold Nanoparticles (Fig 5) and, $8 \%$ were aware of Gene Diagnostic properties of Gold Nanoparticles (Fig 6).

\section{Discussion}

Human cells and biological molecules such as enzymes, receptors, and antibodies are larger than nanoparticles. These nanoparticles have an extraordinary interaction with proteins on the surface and inside the cell due to their size range, making them useful in cancer diagnosis and treatment. Surgery, chemotherapy, and radiation therapy are all common cancer treatments. Photothermal therapy

Figure 1. Awareness of the medicinal applications of Gold Nanoparticles.

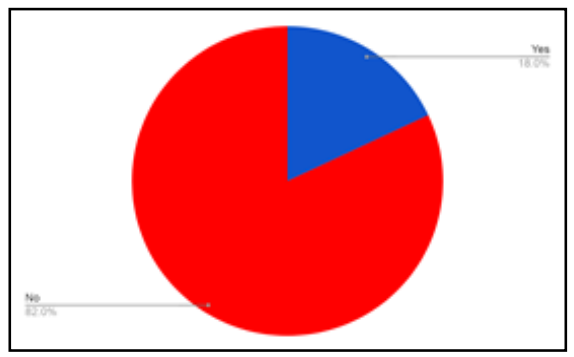

Figure 2. Awareness of the anti-cancer properties of Gold Nanoparticles.

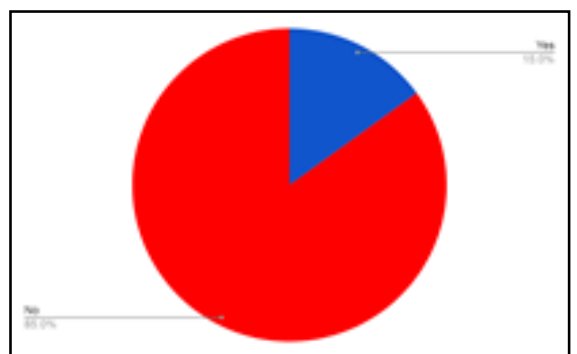

Figure 3. Awareness of biodelivery applications of Gold Nanoparticles.

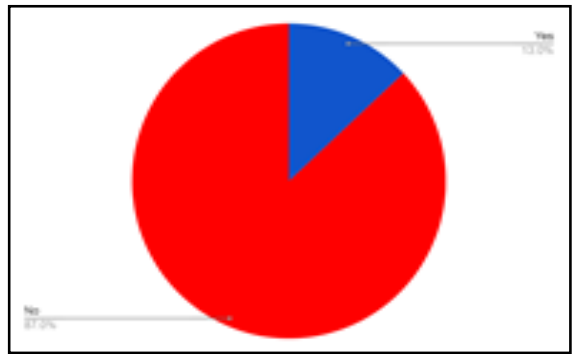

Figure 4. Awareness of photothermal effects of Gold Nanoparticles.

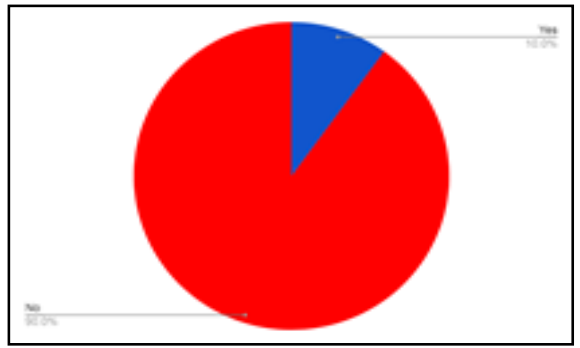


Figure 5. Awareness of DNA detection properties of Gold Nanoparticles.

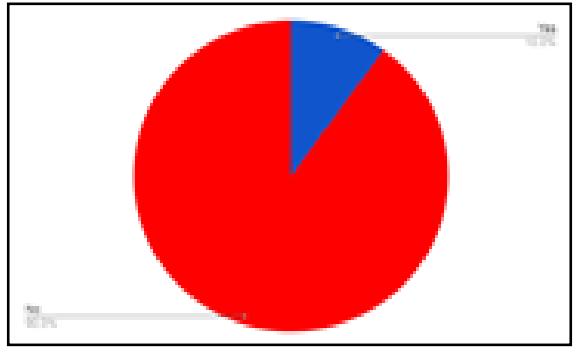

Figure 6. Awareness of Gene Diagnostic properties of Gold Nanoparticles

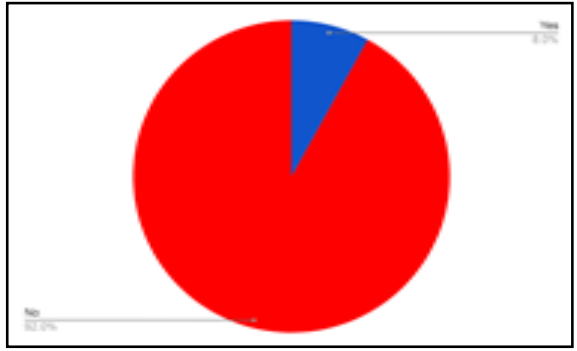

is used in gold nanoparticle-based cancer therapy to kill cancer and tumour cells. When bombarded with focussed big impulses of an appropriate wavelength, targeted gold nanoparticles can kill cancer cells $[18,19]$.

The formation of nanoclusters on the cell membrane was studied by Zharov et al., When compared to normal cells without nanoclusters, it was discovered that the creation of nanoclusters increased local absorption and redshifting. The introduction of a near-infrared (NIR) laser resulted in a significant improvement in laser-induced cancer cell death [20]. Hirsch et al., investigated the photothermally induced morbidity of human breast cancer cells cultured with gold nanoshells when exposed to near-infrared light [21].

In vivo studies showed that lower NIR light exposure caused a significant average temperature rise in solid tumours treated with gold nanoshells, which is capable of causing irreversible tissue damage, whereas controls exposed to NIR light had a much lower average temperature and appeared unaffected. In 2008, Zheng et al., demonstrated that gold nanoparticles can increase radioactivity by increasing ionising radiation absorption, causing single- and double-stranded DNA to break [22].

Large macromolecules can be delivered using gold nanoparticles. They are effective for the delivery of biomolecules because of their adjustable size and functionality. Proteins could be delivered effectively using gold nanoparticles. According to Verma et al., cationic tetraalkyl ammonium functionalized gold nanoparticles can identify the surface of anionic proteins and block their activity by complementary electrostatic interactions [23]. The activity was restored thanks to the release of free protein, which was achieved by using GSH to treat the protein-particle complex. This demonstrated that gold nanoparticles can function as protein transporters. Functionalized gold nanoparticles as insulin carriers were also proven by Bhumkar et al., [24]. Chitosan, a harmless biopolymer, was used to coat the nanoparticles in order to stabilise them. Insulin adsorbs significantly on the surface of Chitosan Coated particles, making them useful for transmucosal administration.

When gold nanoparticles are irradiated with light, the excited conduction band electrons return to their ground state by releasing their energy as heat into the surrounding medium, making gold nanoparticles 'nanoheaters' . Depending on the laser power, time of irradiation, and concentration of gold nanoparticles in the spot size of the laser source, the temperature rises from $10 \mathrm{C}$ to approximately $1000 \mathrm{C}$. The photothermal effect is the essential premise for gold nanoparticles' potential therapeutic utility, in addition to its delivery application. The use of gold nanoparticles in photothermal tumour ablation has been described by Huang et al., [25].

The detection of DNA using gold nanoparticles has been widely reported and discussed. For the detection of DNAassay, some of the approaches are summarised here. Hill et al., created a new biobarcode test that uses blocking strands to prevent the target from rehybridizing and enables for the detection of double stranded genomic DNA [26]. Using gold nanoparticles and dynamic light scattering measurement, Dai et al. devised a one-step homogeneous DNA detection method with great sensitivity [27].

The use of gold nanoparticles in an electrochemical device allows for more accurate and efficient gene diagnostics. Wang et al. reported the use of colloidal gold nanoparticles for electronic DNA hybridization detection in 2001 [28]. They used high-sensitivity anodic stripping electrochemical measurement to capture gold nanoparticles on a hybridised target, followed by high-sensitivity anodic stripping electrochemical detection of the metal tracer. The detection limit of this approach is in the picomolar range. Gold nanoparticles have outstanding catalytic activity due to their high surface area to volume ratio. For the design and production of electrocatalysts, gold nanoparticles have been widely explored. Cell biomolecules such as glucose, norepinephrine, dopamine, catechol, epinephrine, and ascorbic acid can be investigated electrochemically using gold nanoparticles [29, 30].

\section{Conclusion}

There is limited awareness amongst dental students about use of Gold nanoparticles therapy in medical applications. Enhanced awareness initiatives and dental educational programmes together 
with increased importance for curriculum improvements that further promote knowledge and awareness of Gold nanoparticles therapy.

\section{References}

[1]. Myroshnychenko V, Rodríguez-Fernández J, Pastoriza-Santos I, Funston AM, Novo C, Mulvaney P, Liz-Marzán LM, García de Abajo FJ. Modelling the optical response of gold nanoparticles. Chem Soc Rev. 2008 Sep;37(9):1792-805. Pubmed PMID: 18762829.

[2]. Alivisatos P. The use of nanocrystals in biological detection. Nat Biotechnol. 2004 Jan;22(1):47-52. Pubmed PMID: 14704706

[3]. Iyer AK, Khaled G, Fang J, Maeda H. Exploiting the enhanced permeability and retention effect for tumor targeting. Drug Discov Today. 2006 Sep;11(17-18):812-8. Pubmed PMID: 16935749.

[4]. Murphy CJ, Gole AM, Stone JW, Sisco PN, Alkilany AM, Goldsmith EC, Baxter SC. Gold nanoparticles in biology: beyond toxicity to cellular imaging. Acc Chem Res. 2008 Dec;41(12):1721-30. Pubmed PMID: 18712884.

[5]. Yguerabide J, Yguerabide EE. Resonance light scattering particles as ultrasensitive labels for detection of analytes in a wide range of applications. J Cell Biochem Suppl. 2001;Suppl 37:71-81. Pubmed PMID: 11842431.

[6]. Hemalatha R, Ganapathy D. Disinfection of Dental Impression- A Current Overview. Journal of Pharmaceutical Sciences and Research;. 2016 Jul;8(7):661-4.

[7]. Ramya G, Pandurangan K, Ganapathy D. Correlation between anterior crowding and bruxism-related parafunctional habits. Drug Invention Today. 2019 Oct 15;12(10)

[8]. Anjum AS, Ganapathy D, Kumar K. Knowledge of the awareness of dentists on the management of burn injuries on the face. Drug Invention Today. 2019 Sep 1;11(9).

[9]. Inchara R, Ganapathy D, Kumar PK. Preference of antibiotics in pediatric dentistry. Drug Invent Today. 2019 Jun 15;11:1495-8.

[10]. Philip JM, Ganapathy DM, Ariga P. Comparative evaluation of tensile bond strength of a polyvinyl acetate-based resilient liner following various denture base surface pre-treatment methods and immersion in artificial salivary medium: An in vitro study. Contemp Clin Dent. 2012 Jul;3(3):298-301. Pubmed PMID: 23293485

[11]. Gupta A, Dhanraj M, Sivagami G. Implant surface modification: review of literature. The Internet Journal of Dental Science. 2009;7(1):10.

[12]. Indhulekha V, Ganapathy D, Jain AR. Knowledge and awareness on biomedical waste management among students of four dental colleges in Chennai, India. Drug Invention Today. 2018 Dec 1;10(12):32-41.

[13]. Mohamed Usman JA, Ayappan A, Ganapathy D, Nasir NN. Oromaxillary prosthetic rehabilitation of a maxillectomy patient using a magnet retained two-piece hollow bulb definitive obturator; a clinical report. Case Rep Dent. 2013;2013:190180. Epub 2013 Mar 4. Pubmed PMID: 23533823.

[14]. Ganapathy DM, Joseph S, Ariga P, Selvaraj A. Evaluation of the influence of blood glucose level on oral candidal colonization in complete denture wearers with Type-II Diabetes Mellitus: An in vivo Study. Dent Res J (Isfahan). 2013 Jan;10(1):87-92.Pubmed PMID: 23878569.

[15]. Menon A, Ganapathy DM, Mallikarjuna AV. Factors that influence the col- our stability of composite resins. Drug Invention Today. 2019 Mar 1;11(3).

[16]. Dhanraj G, Rajeshkumar S. Anticariogenic Effect of Selenium Nanoparticles Synthesized Using Brassica oleracea. Journal of Nanomaterials. $2021 \mathrm{Jul}$ $10 ; 2021$.

[17]. Ganapathy D, Department of Prostodontics, Saveetha Dental College, Saveetha Institute of Medical and Technical Sciences, - C, India. Nanobiotechnology in combating CoVid-19 [Internet]. Vol. 16, Bioinformation. 2020. p. 828-30. Available from:

[18]. Huang X, Qian W, El-Sayed IH, El-Sayed MA. The potential use of the enhanced nonlinear properties of gold nanospheres in photothermal cancer therapy. Lasers Surg Med. 2007 Oct;39(9):747-53. Pubmed PMID: 17960762.

[19]. Tong L, Zhao Y, Huff TB, Hansen MN, Wei A, Cheng JX. Gold Nanorods Mediate Tumor Cell Death by Compromising Membrane Integrity. Adv Mater. 2007:19:3136-3141. 200701974.Pubmed PMID: 19020672.

[20]. Zharov VP, Galitovskaya EN, Johnson C, Kelly T. Synergistic enhancement of selective nanophotothermolysis with gold nanoclusters: potential for cancer therapy. Lasers Surg Med. 2005 Sep;37(3):219-26. Erratum in: Lasers Surg Med. 2005 Oct;37(4):329.Pubmed PMID: 16175635.

[21]. Hirsch LR, Stafford RJ, Bankson JA, Sershen SR, Rivera B, Price RE, Hazle JD, Halas NJ, West JL. Nanoshell-mediated near-infrared thermal therapy of tumors under magnetic resonance guidance. Proc Natl Acad Sci U S A. 2003 Nov 11;100(23):13549-54. Epub 2003 Nov 3.Pubmed PMID: 14597719.

[22]. Zheng Y, Hunting DJ, Ayotte P, Sanche L. Radiosensitization of DNA by gold nanoparticles irradiated with high-energy electrons. Radiat Res. 2008 Jan;169(1):19-27. Erratum in: Radiat Res. 2008 Apr;169(4):481-2. Pubmed PMID: 18159957.

[23]. Verma A, Simard JM, Worrall JW, Rotello VM. Tunable reactivation of nanoparticle-inhibited $\bigotimes$-galactosidase by glutathione at intracellular concentrations. Journal of the American chemical society. 2004 Nov 3;126(43):1398791.

[24]. Bhumkar DR, Joshi HM, Sastry M, Pokharkar VB. Chitosan reduced gold nanoparticles as novel carriers for transmucosal delivery of insulin. Pharm Res. 2007 Aug;24(8):1415-26. Pubmed PMID: 17380266.

[25]. Huang X, Jain PK, El-Sayed IH, El-Sayed MA. Plasmonic photothermal therapy (PPTT) using gold nanoparticles. Lasers Med Sci. 2008 Jul;23(3):217-28. Pubmed PMID: 17674122.

[26]. Hill HD, Vega RA, Mirkin CA. Nonenzymatic detection of bacterial genomic DNA using the bio bar code assay. Anal Chem. 2007 Dec 1;79(23):921823. Pubmed PMID: 17927207.

[27]. Dai Q, Liu X, Coutts J, Austin L, Huo Q. A one-step highly sensitive method for DNA detection using dynamic light scattering. J Am Chem Soc. 2008 Jul 2;130(26):8138-9. Pubmed PMID: 18540598.

[28]. Wang J, Xu D, Kawde AN, Polsky R. Metal nanoparticle-based electrochemical stripping potentiometric detection of DNA hybridization. Anal Chem. 2001 Nov 15;73(22):5576-81. Pubmed PMID: 11816590.

[29]. Wang L, Bai J, Huang P, Wang H, Zhang L, Zhao Y. Self-assembly of gold nanoparticles for the voltammetric sensing of epinephrine. Electrochemistry communications. 2006 Jun 1;8(6):1035-40.

[30]. Wang J, Wang F, Zou X, Xu Z, Dong S. Surface plasmon resonance and electrochemistry for detection of small molecules using catalyzed deposition of metal ions on gold substrate. Electrochemistry communications. 2007 Feb 1;9(2):343-7. 